\title{
Isolamento e seleção de fungos tolerantes ao herbicida Glyphosate
}

\author{
Isolation and selection of Glyphosate herbicide tolerant fungi \\ Aislamiento y selección de hongos tolerantes a herbicidas Glyphosate
}

Felipe Soares de Souza

ORCID: https://orcid.org/0000-0003-2955-670X Universidade do Estado de Mato Grosso, Brasil

E-mail: felipe.soares@unemat.br

Hilton Marcelo de Lima Souza

ORCID: https://orcid.org/0000-0001-9159-6847 Universidade do Estado de Mato Grosso, Brasil E-mail: hilton.marcelo@unemat.br

João Arthur dos Santos Oliveira

ORCID: https://orcid.org/0000-0001-6864-1523

Universidade Estadual de Maringá, Brasil

E-mail: joaoarthur_oliveira@hotmail.com

João Alencar Pamphile

ORCID: https://orcid.org/0000-0002-6139-5937

Universidade Estadual de Maringá, Brasil E-mail:prof.pamphile@gmail.com

Julio Cesar Polonio

ORCID: https://orcid.org/0000-0001-6864-1523 Universidade Estadual de Maringá, Brasil E-mail: jcpolonio2@uem.br Miriam Hiroko Inoue

ORCID: https://orcid.org/0000-0002-5332-5170 Universidade do Estado de Mato Grosso, Brasil E-mail: miriam@unemat.br

\begin{abstract}
Resumo
O objetivo desse trabalho foi isolar fungos de uma reserva ecológica do Centro-Oeste brasileiro e selecionar espécies tolerantes ao glyphosate, um herbicida amplamente utilizado na agricultura. Os isolados purificados foram submetidos a ensaios qualitativos para avaliar a capacidade de oxidação do ácido gálico e descoloração do corante RBBR. Em seguida, os fungos selecionados foram identificados por meio de técnicas de biologia molecular e utilizados em testes de tolerância ao herbicida. Foram avaliadas as taxas de crescimento fúngico $(\mathrm{CF})$ e inibição de crescimento fúngico (ICF) na ausência e presença de diferentes concentrações de glyphosate $\left(10 \mathrm{mg} \mathrm{mL}^{-1}, 30 \mathrm{mg} \mathrm{mL}^{-1}\right.$ e $\left.50 \mathrm{mg} \mathrm{mL}^{-1}\right)$. Para análise estatística foi utilizado esquema fatorial duplo (fungo e concentração), seguida do teste de Tukey $(\mathrm{p} \leq 0,05)$. Um total de 44 fungos foram isolados a campo, tendo uma eficiência de purificação de 50\%. Destes, $60 \%$ mostraram resultados positivos no teste do ácido gálico e $45,5 \%$ obtiveram resultado positivo quanto a descoloração do RBBR. Os sete fungos selecionados a partir dos testes qualitativos foram tolerantes ao herbicida glyphosate, destacando-se Phanerochaete australis SA18 com maior CF, menor ICF e crescimento micelial significativamente maior em comparação com outros fungos em todos os ensaios. Assim, recomenda-se o uso de P. australis SA18 para novos estudos sobre produção de enzimas ligninolíticas, degradação e produção de metabólitos de glyphosate e ensaios sobre biorremediação de solos agrícolas contaminados.
\end{abstract}

Palavras-chave: Biorremediação; Fenoloxidases; Xenobióticos; Herbicidas.

\begin{abstract}
The objective of this work was to isolate fungi from an ecological reserve in the Brazilian Midwest and to select species tolerant to glyphosate, a herbicide widely used in agriculture. The purified isolates were subjected to qualitative tests to assess the oxidizing capacity of gallic acid and RBBR dye discoloration. Then, the selected fungi were identified through molecular biology techniques and used in herbicide tolerance tests. Fungal growth rates (FG) and fungal growth inhibition (FGI) in the absence and presence of different concentrations of glyphosate $\left(10 \mathrm{mg} \mathrm{mL}^{-1}\right.$, $30 \mathrm{mg} \mathrm{mL}^{-1}$ and $50 \mathrm{mg} \mathrm{mL}^{-1}$ ) were evaluated. For statistical analysis, a double factorial scheme (fungus and concentration) was used, followed by the Tukey test $(p \leq 0.05)$. A total of 44 fungi were isolated in the field, having a purification efficiency of 50\%. Of these, $60 \%$ showed positive results in the gallic acid test and $45.5 \%$ were positive for RBBR discoloration. The seven fungi selected from the qualitative tests were tolerant to the herbicide glyphosate, with Phanerochaete australis SA18 standing out with higher FG, lower FGI and mycelial growth significantly higher
\end{abstract}


compared to other fungi in all tests. Thus, the use of P. australis SA18 is recommended for further studies on the production of ligninolytic enzymes, degradation and production of glyphosate metabolites and tests on bioremediation of contaminated agricultural soils.

Keywords: Bioremediation; Phenoloxidases; Xenobiotics; Herbicides.

\section{Resumen}

El objetivo de este trabajo fue aislar hongos de una reserva ecológica en el Medio Oeste brasileño y seleccionar especies tolerantes al glifosato, un herbicida ampliamente utilizado en la agricultura. Los aislados purificados se sometieron a pruebas cualitativas para evaluar la capacidad oxidante del ácido gálico y la decoloración del tinte RBBR. Luego, los hongos seleccionados fueron identificados mediante técnicas de biología molecular y utilizados en pruebas de tolerancia a herbicidas. Se evaluaron las tasas de crecimiento fúngico $(\mathrm{CF})$ y la inhibición del crecimiento fúngico (ICF) en ausencia y presencia de diferentes concentraciones de glifosato $\left(10 \mathrm{mg} \mathrm{mL}^{-1}, 30 \mathrm{mg} \mathrm{mL}^{-1}\right.$ y $50 \mathrm{mg}$ $\mathrm{mL}^{-1}$ ). Para el análisis estadístico se utilizó un esquema factorial doble (hongo y concentración), seguido de la prueba de Tukey $(\mathrm{p} \leq 0.05)$. Se aislaron en campo un total de 44 hongos, con una eficiencia de purificación del $50 \%$. De estos, el $60 \%$ mostró resultados positivos en la prueba del ácido gálico y el 45,5\% fueron positivos para la decoloración de RBBR. Los siete hongos seleccionados de las pruebas cualitativas fueron tolerantes al herbicida glifosato, destacándose Phanerochaete australis SA18 con mayor CF, menor ICF y crecimiento micelial significativamente mayor en comparación con otros hongos en todas las pruebas. Por lo tanto, se recomienda el uso de P. australis SA18 para estudios adicionales sobre la producción de enzimas ligninolíticas, degradación y producción de metabolitos de glifosato y pruebas de biorremediación en suelos agrícolas contaminados.

Palabras clave: Biorremediación; Fenoloxidasas; Xenobióticos; Herbicidas.

\section{Introdução}

O uso de pesticidas para o controle de pragas e doenças agrícolas vem aumentando a pouco mais de meio século e tem duplicado nas últimas décadas. Uma avaliação do risco global de noventa e dois ingredientes de pesticidas ativos sugere que 2,5 bilhões de hectares de terras agrícolas estejam sob risco de poluição por mais de um ingrediente ativo. O aumento da população, a crise de alimento e o advento de cultivares transgênicas resistentes a certos pesticidas vem sendo relatada como alguns dos principais motivos dessa expansão (Moraes \& Rossi, 2010; Mahmood et al., 2016; Maggi et al., 2020; Hough, 2021).

O Brasil possui uma das maiores áreas agricultáveis do mundo, sendo o maior consumidor de herbicidas, totalizando cerca de um milhão de toneladas por ano. O glyphosate (N-(fosfonometil)glicina), composto não seletivo pertencente ao grupo das glicinas, que apresenta amplo espectro de controle de plantas daninhas anuais e perenes, é contido em mais de 750 produtos comerciais, sendo o herbicida mais utilizado no mundo. Dessa forma, o seu uso nos mais diversos setores da agricultura tem levado a uma ampla disseminação ambiental (Pietrobon \& Senem, 2015; Landrigan \& Belpoggi, 2018; Zhan et al., 2018; Barroso \& Murata, 2021).

O uso intensivo de glyphosate tem levado à contaminação de águas subterrâneas, superficiais e do solo. Os resíduos desses pesticidas podem afetar a microbiota, plantas, animais e permanecer na cadeia alimentar por meio de bioacumulação (Eman et al., 2013; Demichelli, 2016; Singh et al., 2020a). Em humanos, os potenciais efeitos negativos sobre a saúde ainda é polêmica e controversa. Recentemente, a Agência de Proteção Ambiental dos Estados Unidos (USEPA) considerou o glyphosate como "improvável de ser cancerígeno". No entanto, a Agência Internacional para Pesquisa sobre Câncer (IARC) concluiu que há "fortes evidências" de que a exposição ao glyphosate é genotóxica, classificando-o como "provavelmente carcinogênico" (Grupo 2A) (Benbrook, 2019; Maggi et al., 2020).

Diante desse atual cenário de contaminação ambiental, faz-se necessário a realização de estudos voltados a mitigação da presença de pesticidas no meio ambiente. Uma das alternativas é a bioprospecção, uma área abrangente que busca extrair certos compostos da biodiversidade e que sejam úteis à humanidade, tais como: enzimas, genes e produtos derivados do metabolismo de microrganismos (fungos, vírus, bactérias, microalgas e protozoários), macrofungos, plantas e animais (Filho, 2014; Saccaro, 2011). Um tipo de bioprospecção ambiental é a biorremediação, processo no qual organismos são utilizados 
tecnologicamente para remover ou reduzir (remediar) poluentes nos ambientes, desde águas superficiais/subterrâneas e solos, até resíduos e efluentes industriais em aterros ou áreas de contenção (Gaylarde et al., 2005).

Dentre os diversos organismos que podem ser utilizados em programas de biorremediação, destacam-se os fungos, por serem capazes de formar uma rede micelial extensa, produzirem enzimas catabólicas de baixa especificidade e terem autonomia no uso de poluentes como substratos para seu crescimento (Harms et al., 2011). Entre os diversos grupos de fungos, aqueles que produzem esporocarpos (basidioma ou ascomas) visíveis a olho nu, pertencentes às classes basidiomicetos e ascomicetos respectivamente, também denominados macrofungos, secretam um complexo de enzimas extracelulares (fenoloxidases) que estão envolvidas no processo de oxidação da lignina e de vários xenobióticos quimicamente estáveis e recalcitrantes (Amazonas, 2003; Bononi, 2008; Lee et al., 2014; Rodríguez, 2014).

Uma das primeiras etapas para implementação de programas de biorremediação de locais contaminados é a seleção de organismos que apresentem potencial para degradar o xenobióticos de interesse. Para a seleção de fungos, a literatura tem demonstrado o uso eficaz de diversos ensaios. Dentre os estudos qualitativos, destacam-se a análise da formação do halo de degradação em meios de cultura contendo ácido gálico e guaiacol, além da capacidade de descoloração do corante têxtil Remazol Brilhante Blue R (RBBR), entre outros (Rodríguez, 2014; Lee et al., 2014). Quanto aos testes quantitativos, a literatura tem demonstrado a realização de estudos sobre a atividade de enzimas do complexo fenoloxidases, tais como lacase e certas peroxidases (Barbosa, 2010; Colla, 2008; Lee et al., 2014), testes in vitro da tolerância aos contaminantes de interesse, bem como de biodegradação, análise de metabólitos e capacidade de mineralização (Argumedo-Delira et al., 2012; Souza et al., 2016; Souza et al., 2017).

Diante deste cenário, trabalhos científicos que visam a seleção de organismos com potencial para uso em biorremediação de ambientes contaminados com glyphosate podem gerar resultados promissores e importantes para mitigação dos impactos ambientais gerados pela presença e acúmulo destes xenobióticos no meio ambiente. No Estado de Mato Grosso, Brasil, região que se destaca a nível nacional e mundial quanto a produção de diversas culturas agrícolas, pesquisas como essa são ainda inexistentes. Desse modo, este trabalho teve como objetivo selecionar fungos isolados de uma área de preservação permanente do Estado de Mato Grosso que apresentem potencial para biorremediação do herbicida glyphosate.

\section{Metodologia}

Os isolados de fungos utilizados neste trabalho foram coletados em fevereiro de 2018 na Estação Ecológica Serra das Araras (EESA), uma área de conservação e proteção integral gerida pelo Instituto Chico Mendes de Conservação da

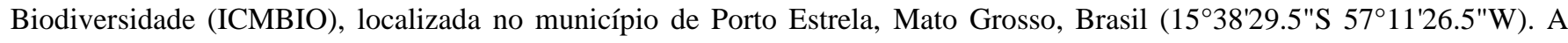
coleta de material biológico foi autorizada pelo Sistema de Autorização e Informação em Biodiversidade (SISBIO), sob $n^{\circ}$ de solicitação 61721. A região da EESA apresenta relevo acidentado, oscilando entre 250 e $900 \mathrm{~m}$ de altura e apresenta uma área de 28.700 hectares, com cerca de $50 \mathrm{~km}$ de comprimento e $8 \mathrm{Km}$ de largura (“Ambiente brasil," n.d., para. 1).

A coleta foi realizada em uma das trilhas existente na EESA, percorrida em seus primeiros 700 metros, local em que são realizados estudos científicos sobre biodiversidade. Os fungos avistados foram coletados utilizando um estilete para obtenção do corpo frutífero juntamente com seu substrato, sendo armazenados em caixas plásticas de polipropileno compartimentada. Em seguida, o material biológico foi encaminhado para o Laboratório da EESA, onde foi realizado o processo de isolamento micelial dos espécimes. Em um ambiente asséptico, assegurado pelo uso de álcool 70\% e lamparina, fragmentos da estrutura reprodutora dos fungos coletados foram retirados com auxílio de um bisturi estéril, que passaram pelo seguinte processo de desinfecção superficial: i) lavagem dos fragmentos dos corpos de frutificação em água destilada; ii) imersão em álcool $70 \%$ por 1 minuto; iii) imersão em hipoclorito de sódio $2 \%$ por 1 minutos; iv) enxágue com água destilada 
esterilizada. Os fragmentos foram inoculados em três diferentes meios de cultura: Batata Dextrose Agar (15 g L ${ }^{-1}$ Ágar, $20 \mathrm{~g} \mathrm{~L}^{-}$

${ }^{1}$ Dextrose, 200g L ${ }^{-1}$ Infusão de batata) (BDA), Extrato de Malte 2\% (20 g L-1 extrato de malte, $15 \mathrm{~g} \mathrm{~L}^{-1}$ Ágar) (MEA 2\%), e Mix com serragem (20 $\mathrm{g} \mathrm{L}^{-1}$ Serragem moída, $20 \mathrm{~g} \mathrm{~L}^{-1}$ farelo de aveia, $20 \mathrm{~g} \mathrm{~L}^{-1}$ ágar, $2 \mathrm{~g} \mathrm{~L}^{-1} \mathrm{CaCO}_{3}$ ) (MS), acrescidos de cloranfenicol 0,1\% e fungicida benomil 0,2\%. Todo o material foi encaminhado ao Laboratório de Microbiologia do Centro de Pesquisas, Estudos e Desenvolvimento Agroambientais (CPEDA) da Universidade do Estado de Mato Grosso (UNEMAT), campus Universitário Professor Eugênio Carlos Stieler, Tangará da Serra. As placas inoculadas foram incubadas a $28^{\circ} \mathrm{C}$ e foi realizado a purificação dos isolados pelo método de esgotamento em estrias em meio de cultura MEA 2\% ou Mix Serragem. Certos espécimes de fungos associados que surgiram durante o isolamento também foram purificados e armazenados.

Alguns isolados foram identificados por taxonomia clássica conforme metodologia de Guerrero e Homrich (1999). Os fungos foram armazenados através do método Castellani (1939), em tubos de ensaio contendo meio BDA, meio MEA 2\% ou Mix Serragem sob refrigeração e em tubos de criopreservação contendo glicerol e meio MEA 2\% (1:1), mantidos em UltraFreezer a $-80^{\circ} \mathrm{C}$.

\subsection{Testes qualitativos: ácido gálico e descoloração do RBBR}

Para avaliar a presença de enzimas do complexo fenoloxidases, foi realizado o teste do ácido gálico (Davidson et al., 1938). A "reação de Banvendam" pode indicar que as enzimas dos fungos podem converter o ácido gálico a quinonas, indicativo do potencial enzimático em degradar compostos aromáticos e xenobióticos (Lee et al., 2020). Para tanto os fungos foram cultivados em meio BDA e incubados a $28^{\circ} \mathrm{C}$ por 7 dias para crescimento micelial. Logo após, foram retirados três discos de $8 \mathrm{~mm}$ de diâmetro da borda da cultura micelial de cada espécime e transferidos para placas de Petri contendo meio MEA $2 \%$ acrescido de ácido gálico a $0,5 \%$. Em seguida, as placas foram mantidas por 5 dias a temperatura de $28{ }^{\circ} \mathrm{C}$ com fotoperíodo de 24 horas. A presença do halo âmbar da reação foi classificado em três níveis: halo âmbar avermelhado (v), âmbar médio (m) e âmbar amarelado (a). Realizou-se a medida do halo âmbar e do crescimento micelial (diâmetro) através de régua milimetrada. Os dados foram realizados em triplicata.

Para a realização do teste de descoloração do corante RBBR, os fungos foram cultivados em meio BDA e incubados a $28{ }^{\circ} \mathrm{C}$ por 7 dias. Logo após, decorreu-se a retirada de três discos de $8 \mathrm{~mm}$ de diâmetro de micélio da cultura pura de cada isolado e transferidos para placas de Petri contendo meio de cultura acrescido de corante RBBR 2\%. Em seguida, as placas foram mantidas por 5 dias a temperatura de $28{ }^{\circ} \mathrm{C}$. No teste com corante RBBR, foi realizada a avaliação da capacidade de descolorir, avaliado como: descoloração total $(* * *)$, mediana $(* *)$ ou fraca $(*)$. O crescimento micelial (diâmetro) também medido e todos os testes foram realizados em triplicata.

Os fungos com os melhores resultados em ambos os testes foram identificados por meio de técnicas de biologia molecular e selecionados para a serem submetidos a ensaios de tolerância ao herbicida glyphosate.

\subsection{Identificação molecular dos isolados de fungos selecionados}

A extração do DNA genômico dos fungos foi realizada com o kit Power Soil de acordo com as instruções do fabricante. A identificação foi baseada nos genes ITS, LSU e $\beta$-Tubulina. As condições de PCR e os primers empregados estão apresentados na Tabela 1. 
Tabela 1: Genes/loci para análise dos fungos, com seus respectivos iniciadores oligonucleotídicos e condições de amplificação por PCR.

\begin{tabular}{|c|c|c|c|c|}
\hline Gene & Primers & Sequência (5' - 3') & Condições de PCR & Referência \\
\hline ITS & $\begin{array}{l}\text { ITS1 } \\
\text { ITS4 }\end{array}$ & $\begin{array}{l}\text { TCCGTAGGTGAACCTGCGG } \\
\text { TCCCCGCTTATTGATATGC }\end{array}$ & $\begin{array}{c}92^{\circ} \mathrm{C}: 4 \mathrm{~min} ;\left(92^{\circ} \mathrm{C} 40 \mathrm{~s}, 52^{\circ} \mathrm{C}, 1 \mathrm{~min} \text { e } 30 \mathrm{~s},\right. \\
\left.72^{\circ} \mathrm{C}, 2 \mathrm{~min}\right) \times 35 \text { ciclos; } 72^{\circ} \mathrm{C}, 5 \mathrm{~min} .\end{array}$ & White et al., (1990). \\
\hline LSU & $\begin{array}{l}\text { LR0R } \\
\text { LR7 }\end{array}$ & $\begin{array}{c}\text { GTACCCGCTGAACTTAAGC } \\
\text { TACTACCACCAAGATCT }\end{array}$ & $\begin{array}{c}94^{\circ} \mathrm{C}: 2 \mathrm{~min} ;\left(94^{\circ} \mathrm{C} 30 \mathrm{~s}, 50^{\circ} \mathrm{C}, 1 \mathrm{~min}, 72^{\circ} \mathrm{C},\right. \\
1 \mathrm{~min}) \mathrm{x} 40 \text { ciclos; } 72^{\circ} \mathrm{C}, 3 \mathrm{~min}\end{array}$ & $\begin{array}{l}\text { Rehner e Samuels (1994) } \\
\text { Vilgalys e Hester (1990) }\end{array}$ \\
\hline$\beta$-Tubulina & $\begin{array}{c}\mathrm{T} 1 \\
\mathrm{Bt}-2 \mathrm{~b} \\
\end{array}$ & $\begin{array}{c}\text { AACATGCGTGAGATTGTAAGT } \\
\text { ACCCTCAGTGTAGTGACCCTTGGC }\end{array}$ & $\begin{array}{l}94^{\circ} \mathrm{C}: 4 \min ;\left(94^{\circ} \mathrm{C} 1 \mathrm{~min}, 55^{\circ} \mathrm{C}, 1 \mathrm{~min}, 72^{\circ}\right. \\
\mathrm{C}, 1 \mathrm{~min}) \times 40 \text { ciclos; } 72^{\circ} \mathrm{C}, 3 \mathrm{~min}\end{array}$ & $\begin{array}{c}\text { O’Donnell e Cigelnik } \\
\text { (1997) } \\
\text { Glass e Donaldson (1995) }\end{array}$ \\
\hline
\end{tabular}

Fonte: Autores.

As sequências foram tratadas e alinhadas utilizando o software Geneious Prime v. 2019.1.1. Uma vez que as sequências mostraram uma grande semelhança no Genbank com outros fungos, realizou-se uma análise filogenética com base em dados filogenéticos pré-estabelecidos. As sequências foram então resgatadas e alinhadas com o MAFFT (Katoh \& Toh, 2008). Após o alinhamento, realizou-se um conjunto bi-loci de sequências. Para análise filogenética baseada na máxima verossimilhança e inferência bayesiana, MrModelTest v. 2.3 (NYLANDER, 2004) foi utilizado para escolher o melhor modelo evolucionário. A árvore filogenética construída usando MrBayes v. 2.2.4 (Ronquist et al., 2012), levou em consideração os parâmetros gerados por MrModelTest, com cadeia de Markov Monte Carlo (MCMC), com desvio padrão médio das frequências divididas 0.01 (1.000.000 gerações). A probabilidade bayesiana é demonstrada nos nós entre cada indivíduo. A árvore foi editada com o FigTree v. 1.4.2 (Rambaut, 2009). As sequências obtidas foram depositadas no GenBank correspondentes ao ITS1-5.8S-ITS2 (números de acessos OK393673 à OK393679), LSU (números de acessos OK383445 à OK383450) e $\beta$-Tubulina (número de acessos OK423453 à OK423454).

\subsection{Testes quantitativos: tolerância ao glyphosate}

Inicialmente, os fungos foram cultivados em meio MEA $2 \%$ e, posteriormente incubados a $28^{\circ} \mathrm{C}$ por 7 dias. Para esse ensaio foi utilizado o Sal de Amônio de glyphosate (Roundup WG) contendo $720 \mathrm{~g} / \mathrm{kg}$ de princípio ativo, produto com maior concentração possível do princípio ativo comercialmente. Através deste produto foi elaborada uma solução estoque com uma concentração de $100 \mathrm{mg} \mathrm{mL}^{-1}$ armazenada em ampolas. Em seguida, alíquotas de diferentes concentrações de glyphosate (10 $\mathrm{mg} \mathrm{mL} \mathrm{m}^{-1}, 30 \mathrm{mg} \mathrm{mL}^{-1}$ e $50 \mathrm{mg} \mathrm{mL}^{-1}$ ) foram aplicadas e espalhada com a alça de Drigalski em placas de Petri contendo meio MEA 0,2\% (2 $\mathrm{g} \mathrm{L}^{-1}$ extrato de malte, $15 \mathrm{~g} \mathrm{~L}^{-1}$ Ágar) em condições assépticas com triplicata por concentração. As placas sem a presença de glifosato compunham o grupo controle. Posteriormente, foi realizado o inóculo de discos (8 mm) das culturas dos fungos no centro de cada placa de Petri preparadas para os ensaios de tolerância. Em seguida foram mantidas por 10 dias a temperatura de $28^{\circ} \mathrm{C}$ com fotoperíodo 24 horas. A análise da tolerância foi realizada medindo o crescimento micelial a cada 24 horas.

A taxa de crescimento fúngico $(\mathrm{CF})$ foi calculado utilizando a fórmula:

$\mathrm{CF}(\%)=\left(\mathrm{D}_{\mathrm{G}} / \mathrm{D}_{\mathrm{C}}\right) \times 100$, no qual o diâmetro da colônia micelial exposta ao glyphosate $\left(\mathrm{D}_{\mathrm{G}}\right)$ é divido pelo diâmetro da colônia micelial do grupo controle $\left(\mathrm{D}_{\mathrm{C}}\right)$.

Concomitantemente foi feito a análise da taxa de inibição de crescimento fúngico (ICF):

ICF $(\%)=100$ - CF, calculado a partir dos resultados da fórmula anterior da taxa de crescimento fúngico (CF) (ARGUMEDODELIRA et al., 2012).

Para análise estatística, foi utilizado o esquema fatorial duplo (fungo e concentração), seguida do teste de Tukey ( $\mathrm{p} \leq$ $0,05)$. 


\section{Resultados}

\subsection{Isolamentos, purificação e seleção qualitativa de fungos}

Foram coletados um total de 44 fungos, fato que impressiona pela biodiversidade encontrada em um pequeno trecho da trilha da EESA. Devido à dificuldades durante o processo de isolamento, apenas 22 fungos foram purificados com êxito. Os fungos tiveram preferência pelo meio MS (17 isolados), seguido de BDA (14 isolados) e MEA 2\% (13 isolados) (Tabela 2A). $\mathrm{O}$ uso de um meio de cultura alternativo com serragem de madeira demonstrou ser uma importante alternativa para isolamentos de macrofungos. Apenas alguns isolados purificados foram identificados a nível de gênero, por meio de taxonomia clássica: SA02 (Marasmius sp1.), SA05 (Marasmius sp3.), SA16 (Cyathus sp.), SA21 (Coprinus sp.), SA25 (Cookeina sp.), SA37 (Lentinus sp4.).

Nos ensaios para avaliar a capacidade de oxidação do ácido gálico, 13 isolados apresentaram resultados positivos, com aparecimento do halo âmbar, porém nem todos tiveram crescimento micelial. Os resultados evidenciam que não há uma relação direta da intensidade do halo âmbar com a capacidade de crescimento do halo e micélio ( $\mathrm{mm}$ ), uma vez que o fungo SA18, que obteve maior crescimento micelial $(80,33 \mathrm{~mm})$ e expressivo tamanho halo âmbar $(52,33 \mathrm{~mm})$, apresentou a coloração do halo com intensidade média (M). Além disso, isolados como halo de intensidade escura (V), tais como SA44 e SA23 (41 mm de halo) não obtiveram crescimento micelial (nulo ou apenas $2 \mathrm{~mm}$, respectivamente) ou muito baixo, como SA07 (7 mm). No entanto, para os fungos SA09 e SA37 obteve-se maior intensidade do halo (V), um dos maiores tamanhos do halo $(53,33 \mathrm{~mm}$ e $44,33 \mathrm{~mm})$, e também se destacou pelo crescimento micelial (30,66 mm e 14,3 $\mathrm{mm})$, respectivamente (Tabela 2B).

Com os testes de descoloração do corante RBBR, 10 fungos apresentaram resultados positivos, sendo possível observar a absorção do corante pelo micélio em dois isolados. Todos isolados obtiveram crescimento micelial na presença do corante têxtil. O resultado de todos os isolados tanto em descoloração do corante e de crescimento micelial estão na Tabela $2 \mathrm{C}$.

De acordo com os resultados, os fungos SA09, SA16, SA18, SA21, SA23 e SA41 apresentaram os melhores níveis de descoloração $(* * *)$, destacando-se SA21 por obter ótimo resultado na descoloração associado ao crescimento micelial $(84 \mathrm{~mm})$, seguido do SA18 $(75 \mathrm{~mm})$ e SA09 com $(48 \mathrm{~mm})$. Outros isolados que apresentaram descoloração fraca $(*)$ e mediana $(* *)$ também obtiveram bons resultados quanto ao crescimento micelial, tais como SA07 (63,6 mm), SA37 (57 mm) e SA44 (80 $\mathrm{mm}$ ), respectivamente. A absorção do corante também foi observada em SA07 e SA37.

Os dados dos testes qualitativos demonstraram o potencial dos isolados SA18, SA09 e SA37 como detentores de enzimas do complexo fenoloxidases, por realizarem a oxidação do ácido gálico e também por apresentarem maior crescimento micelial. Esses mesmos isolados também foram capazes de realizar a descoloração total do RBBR bem como os demais isolados SA16, SA21, SA23, SA37, SA41. Assim, esses isolados foram selecionados para identificação molecular e realização dos testes de tolerância ao herbicida glyphosate. Devido a capacidade de absorver o corante, o isolado SA 07 também foi selecionado. No entanto, SA21 não se adaptou ao meio de cultura utilizado nesse trabalho e por isso não foi utilizado. 
Tabela 2: Resultados dos testes com ácido gálico e descoloração de RBRR por fungos isolados da EESA, Mato Grosso, Brazil.

\begin{tabular}{|c|c|c|c|c|c|c|c|c|c|c|}
\hline \multirow{3}{*}{ Isolados fúngicos } & \multicolumn{3}{|c|}{ A } & \multicolumn{4}{|c|}{ B } & \multicolumn{3}{|c|}{$\mathbf{C}$} \\
\hline & \multicolumn{3}{|c|}{ Isolamento } & \multicolumn{4}{|c|}{ Teste do Ácido Gálico } & \multicolumn{3}{|c|}{ Teste com corante RBBR } \\
\hline & MS & BDA & MEA2\% & Resultado & Coloração & $\begin{array}{l}\text { Halo } \\
(\mathbf{m m})\end{array}$ & $\begin{array}{c}\text { Micélio } \\
(\mathbf{m m})\end{array}$ & Resultado & Descoloração & $\begin{array}{c}\text { Micélio } \\
(\mathrm{mm})\end{array}$ \\
\hline SA01 & + & + & + & - & - & - & - & - & - & - \\
\hline SA02 & + & + & + & + & M & 30,33 & - & - & - & 47,00 \\
\hline SA03 & - & - & - & - & - & - & - & - & - & - \\
\hline SA04 & - & - & - & - & - & - & - & - & - & - \\
\hline SA05 & + & - & - & + & V & 38,66 & 3,30 & - & - & 54,60 \\
\hline SA06 & + & + & - & - & - & - & - & - & - & - \\
\hline SA07 & - & + & - & + & V & 42,66 & 7,00 & +- & $*$ & 63,60 \\
\hline SA08 & - & - & - & - & - & - & - & - & - & - \\
\hline SA09 & + & + & + & + & V & 53,33 & 30,66 & + & $* * *$ & 48,00 \\
\hline SA10 & + & - & + & - & - & - & - & - & - & - \\
\hline SA11 & + & + & + & - & - & - & - & - & - & - \\
\hline SA12 & - & - & - & - & - & - & - & - & - & - \\
\hline SA13 & - & - & - & - & - & - & - & - & - & - \\
\hline SA15 & - & - & + & - & - & - & - & - & - & 44,00 \\
\hline SA16 & + & - & + & + & $\mathrm{M}$ & 36,33 & - & + & $* * *$ & 32,60 \\
\hline SA17 & - & - & - & - & - & - & - & - & - & - \\
\hline SA18 & - & - & + & + & $\mathrm{M}$ & 52,33 & 80,33 & + & $* * *$ & 75,00 \\
\hline SA19 & - & - & - & - & - & - & - & - & - & - \\
\hline SA20 & - & - & - & - & - & - & - & - & - & - \\
\hline SA21 & + & - & - & - & - & - & - & + & $* * *$ & 84,00 \\
\hline SA22 & - & + & - & - & - & - & - & - & - & - \\
\hline $\mathrm{SA} 23$ & - & - & + & + & V & 41,00 & 2,00 & + & $* * *$ & 46,00 \\
\hline SA24 & + & + & - & - & - & - & - & - & - & - \\
\hline SA25 & - & + & - & + & A & 26,00 & - & - & - & 38,00 \\
\hline SA26 & - & - & - & - & - & - & - & - & - & - \\
\hline SA27 & + & - & - & - & - & - & - & - & - & - \\
\hline SA28 & + & - & - & + & A & 25,00 & - & - & - & 34,00 \\
\hline SA29 & + & + & + & - & - & - & - & - & - & 37,33 \\
\hline SA30 & - & - & - & - & - & - & - & - & - & - \\
\hline SA31 & - & - & - & - & - & - & - & - & - & - \\
\hline SA32 & - & - & - & - & - & - & - & - & - & - \\
\hline SA34 & - & - & + & + & V & 40,33 & 10,00 & - & - & 58,00 \\
\hline SA35 & - & - & - & - & - & - & - & - & - & - \\
\hline SA36 & - & - & - & - & - & - & - & - & - & - \\
\hline SA37 & + & + & - & + & V & 44,33 & 14,30 & + & $*$ & 57,00 \\
\hline SA38 & + & - & - & - & - & - & - & - & - & - \\
\hline SA39 & - & - & + & - & - & - & - & - & - & 34,00 \\
\hline SA40 & - & - & + & - & - & - & - & - & - & 62,00 \\
\hline SA41 & - & + & - & - & - & - & - & + & $* * *$ & 33,00 \\
\hline SA42 & + & + & + & - & - & - & - & - & - & 84,00 \\
\hline SA43 & - & - & - & - & - & - & - & - & - & - \\
\hline SA44 & + & + & + & + & V & 41 & - & + & $* *$ & 80,00 \\
\hline SA46 & - & + & - & - & - & - & - & - & - & 49,70 \\
\hline SA47 & - & + & - & + & M & 30,33 & - & +- & $*$ & 30,00 \\
\hline
\end{tabular}

(+) resultado positivo; (-) resultado negativo; (+ -) resultado positivo por absorção micelial; (V) halo âmbar avermelhado; (M) halo âmbar médio; (A) halo âmbar amarelado; Descoloração total $(* * *)$; descoloração média $(* *)$; descoloração fraca $(*)$. Fonte: Autores. 


\subsection{Identificação molecular dos fungos selecionados}

Os dados de identidade com as sequencias gênicas ITS, LSU e $\beta$-Tubulina do GenBank e os cladogramas representando as análises filogenéticas estão representados na Tabela 3 e Figuras 1 A, B, C.

Tabela 3: Fungos e sequências com maior similaridade de acordo com o GenBank (NCBI).

\begin{tabular}{ccccc}
\hline Isolado & Gene & Fungo com maior similaridade & \% de identidade & Acesso no GenBank \\
\hline \multirow{2}{*}{ SA16 } & ITS & Cyathus bulleri & 86.40 & $\underline{\text { MK020156.1 }}$ \\
& LSU & Cyathus bulleri & 100 & $\underline{\text { MK020156.1 }}$ \\
\hline \multirow{2}{*}{ SA23 } & ITS & Polyporus tricholoma & 95.11 & $\underline{\text { AF516541.1 }}$ \\
& LSU & Polyporus thailandensis & 99.85 & $\underline{\text { KX851645.1 }}$ \\
\hline \multirow{2}{*}{ SA09 } & ITS & Disporotrichum dimorphosporum & 99.57 & $\underline{\text { MH859776.1 }}$ \\
\hline \multirow{2}{*}{ SA07 } & ITS & Diaporthe novem & 96.02 & MH864503.1 \\
& B-Tubulina & Diaporthe mayteni & 92.97 & $\underline{\text { KC344107.1 }}$ \\
& LSU & Diaporthe maritima & 99.55 & $\underline{\text { NG_069330.1 }}$ \\
\hline \multirow{2}{*}{ SA37 } & ITS & Lentinus crinitus & 97.38 & $\underline{\text { MH915574.1 }}$ \\
& LSU & Lentinus sajor-caju & 100 & $\underline{\text { KX900181.1 }}$ \\
\hline \multirow{2}{*}{ SA18 } & ITS & Phanerochaete chrysosporium & 96.24 & $\underline{\text { MH047187.1 }}$ \\
& LSU & Phanerochaete livecens & 100 & $\underline{\text { MT248151.1 }}$ \\
\hline \multirow{2}{*}{ SA41 } & ITS & Hypoxylon fendleri & 99.35 & $\underline{\text { MN056423.1 }}$ \\
& B-Tubulina & Hypoxylon fendleri & 92.24 & $\underline{\text { MK908137.1 }}$ \\
\hline
\end{tabular}

Fonte: Autores.

Figura 1: Cladograma resultante da análise bayesiana dos isolados fúngicos SA09, SA16, SA18, SA23, SA37 com o alinhamento bi-loci dos genes ITS e LSU combinados. *SA09= Apenas ITS. **Flavodon flavus (AB971171.1) foi utilizado como grupo externo (A); cladogramas dos isolados fúngicos SA07(B) e AS41 (C) com o alinhamento bi-loci dos genes ITS e $\beta$-Tubulina combinados. *Diaporthella corylina CBS 121124 e *Xylaria hypoxylon CBS 122620 foram utilizados como grupo externo, respectivamente. A probabilidade bayesiana esta demonstrada nos nós entre cada indivíduo.
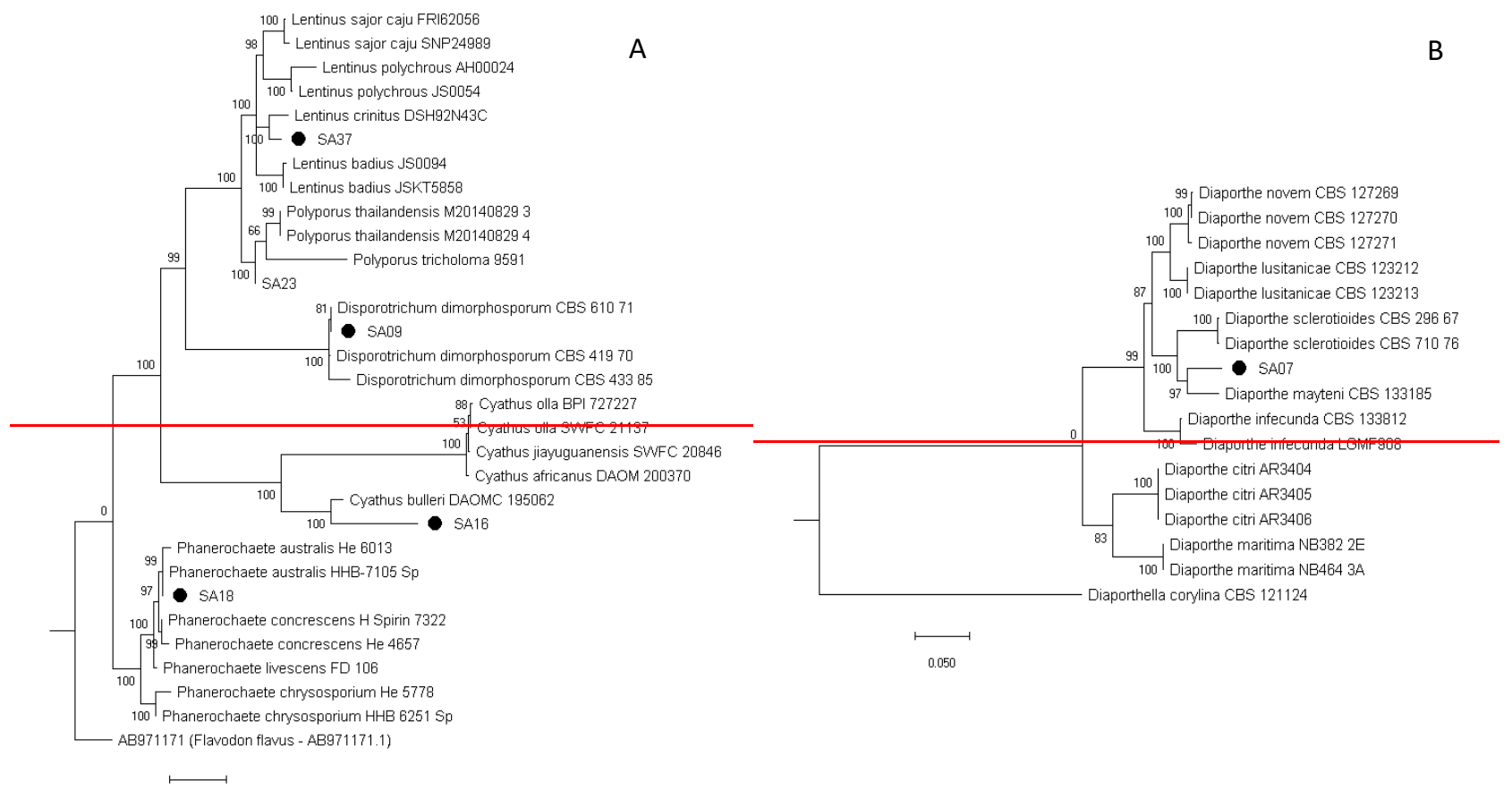

0.050 


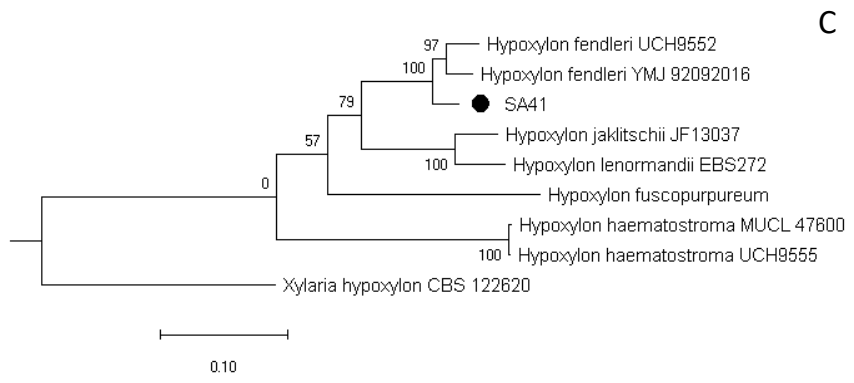

Fonte: Autores.

De acordo com as análises, cinco isolados foram classificados pertencentes ao filo Basidiomycota e confirmados a nível taxonômico de espécie como Cyathus bulleri SA16 (100\% de bootstrap), Disporotrichum dimorphosporum SA09 (100\% de bootstrap), Lentinus crinitus SA37 (100\% de bootstrap), Phanerochaete australis SA18 (97\% de bootstrap) e Polyporus sp. SA23 (100\% de bootstrap) em nível taxonômico de gênero. Os isolados SA07 e SA41 também foram identificados em nível taxonômico pertencente ao filo Ascomycota sendo Diaporthe mayteni (97\% de bootstrap) e Hypoxylon fendleri (100\% de bootstrap), respectivamente como pode ser visto nos cladogramas na Figura 1.

\subsection{Teste de tolerância ao herbicida glyphosate}

Os resultados dos ensaios de tolerância ao $5^{\circ}$ dia demonstraram que a taxa de crescimento fúngico (CF) diminui conforme o aumento da concentração de glyphosate, consequentemente, a taxa de inibição do crescimento (ICF) aumenta nas maiores dosagens do contaminante, como esperado (Fig. 2A). P. australis SA18 obteve a maior taxa de CF na concentração de 10mg (84\%), seguido de $H$. fendleri SA41 (68,5\%) e C. bulleri SA16 (52\%). Contudo, nas concentrações de 30mg e $50 \mathrm{mg}$ as maiores taxas de CF foram de $H$. fendleri SA41 (60,5\% e 57\% respectivamente), demonstrando uma perda de crescimento com aumento da concentração do contaminante. À vista disso, os resultados da taxa de inibição do crescimento (ICF) constatam que uma maior concentração de glyphosate interferem no crescimento micelial dos isolados (Fig. 2B). Polyporus sp. SA23 obteve as maiores taxas de ICF entre os isolados (73,5\% a $84 \%)$, demonstrando sua pouca capacidade de tolerar a presença do contaminante.

O crescimento micelial médios dos fungos sob diferentes concentrações do herbicida glyphosate ao $5^{\circ}$ dias de ensaio está apresentado na Tabela 4. Na ausência do glyphosate (controle), o micélio dos fungos Disporotrichum dimorphosporum SA09, Phanerochaete australis SA18 cresceram totalmente na placa de Petri. Também pode-se notar o baixo crescimento do SA41 no controle, em comparação aos outros fungos. Os dados demonstraram que P. australis SA18 apresentou crescimento micelial estatisticamente distinto dos demais fungos na concentração de $10 \mathrm{mg} / \mathrm{mL}(\mathrm{p} \leq 0,05)$, igualando-se ao grupo controle e demonstrando a habilidade dessa espécie em tolerar glyphosate (Tabela 4). Nesses primeiros dias do ensaio da tolerância foi possível observar que as maiores concentrações de glyphosate $(30 \mathrm{mg} / \mathrm{mL}$ e $50 \mathrm{mg} / \mathrm{mL})$ induziu a um menor crescimento micelial, como esperado. 
Figura 2: Taxa de crescimento fúngico (CF) (A) e Taxa de inibição do crescimento (ICF) (B) do $5^{\circ}$ dia.

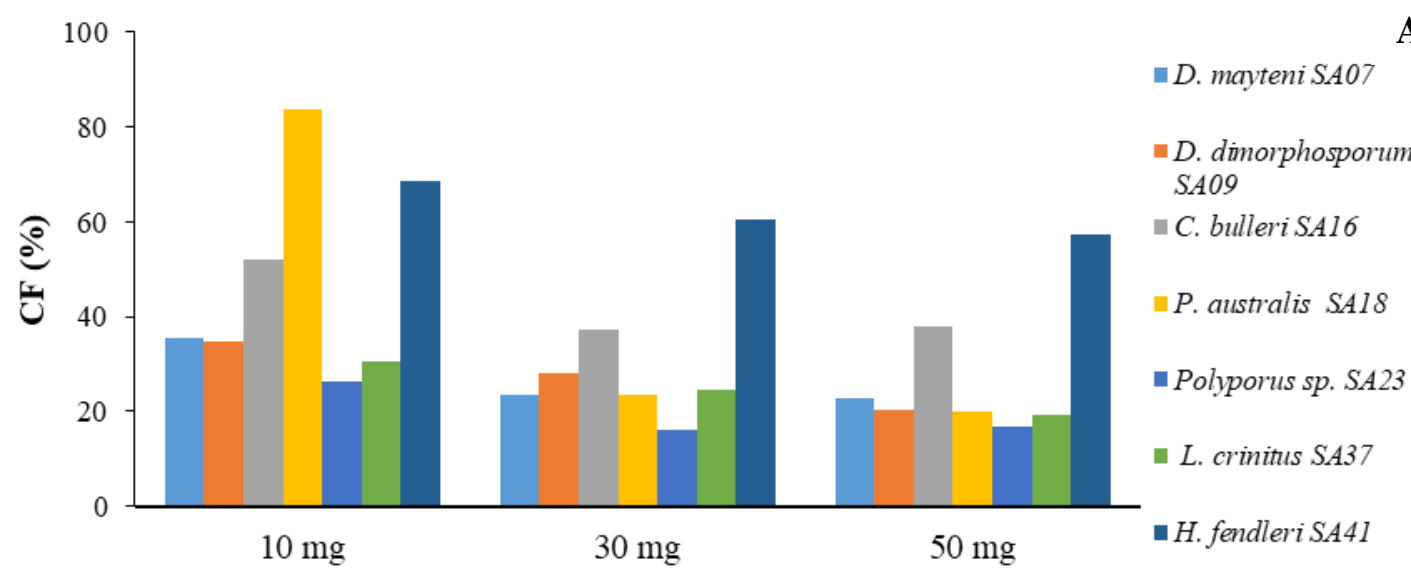

Concentração de glyphosate

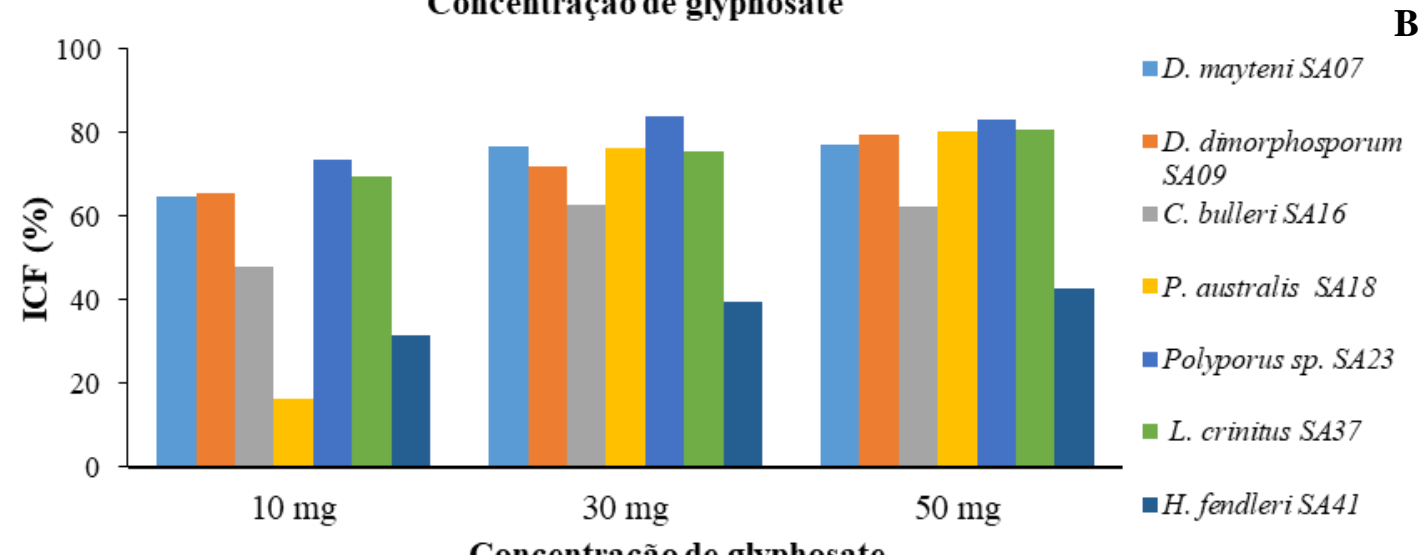

Concentração de glyphosate

Fonte: Autores.

Tabela 4: Crescimento radial $(\mathrm{mm})$ depois de 5 dias em contato com diferentes concentrações de glyphosate.

\begin{tabular}{lccccccc}
\hline \multicolumn{7}{c}{ Fungos } \\
\hline & D. mayteni & D. dimorphosporum & C. bulleri & P. australis & Polyporus sp. & L. crinitus & H. fendleri \\
& SA07 & SA09 & SA16 & SA18 & SA23 & SA37 & SA41 \\
\hline Controle & $39,89 \pm 1,70 \mathrm{Ab}$ & $48,00 \pm 0 \mathrm{Aa}$ & $21,44 \pm 0,37 \mathrm{Ad}$ & $34,44 \pm 0,30 \mathrm{Ac}$ & $34,44 \pm 0,30 \mathrm{Ac}$ & $36,94 \pm 0,63 \mathrm{Abc}$ & $13,22 \pm 0,96 \mathrm{Ae}$ \\
$\mathbf{1 0} \mathbf{~ m ~} \mathbf{~ m L}^{-\mathbf{1}}$ & $14,17 \pm 0,11 \mathrm{Bbc}$ & $16,67 \pm 1,89 \mathrm{Bb}$ & $11,17 \pm 0,33 \mathrm{Bcd}$ & $9,11 \pm 1,19 \mathrm{Bd}$ & $9,11 \pm 1,19 \mathrm{Bd}$ & $11,33 \pm 0,67 \mathrm{Bcd}$ & $9,06 \pm 0,19 \mathrm{Bd}$ \\
$\mathbf{3 0} \mathbf{~ m ~} \mathbf{~ m L}^{-\mathbf{1}}$ & $9,31 \pm 0,30 \mathrm{Cabc}$ & $13,44 \pm 0,59 \mathrm{BCa}$ & $8,00 \pm 0,89 \mathrm{Bbc}$ & $5,56 \pm 0,52 \mathrm{Bc}$ & $5,56 \pm 0,52 \mathrm{Bc}$ & $9,11 \pm 1,26 \mathrm{BCabc}$ & $8,00 \pm 0,56 \mathrm{Bbc}$ \\
$\mathbf{5 0} \mathbf{~ m ~} \mathbf{~ m L}^{-\mathbf{1}}$ & $9,11 \pm 0,41 \mathrm{Ca}$ & $9,81 \pm 2,43 \mathrm{Ca}$ & $8,11 \pm 0,30 \mathrm{Ba}$ & $5,83 \pm 1 \mathrm{Ba}$ & $5,83 \pm 1 \mathrm{Ba}$ & $7,14 \pm 1,69 \mathrm{Ca}$ & $7,56 \pm 0,30 \mathrm{Ca}$ \\
$\mathbf{C V} \mathbf{\%}$ & & & & $10,73 \%$ & & & \\
\hline
\end{tabular}

Médias seguidas de mesma letra, minúscula na coluna e maiúscula na linha, não diferem entre si pelo teste de Tukey $(\mathrm{p} \leq 0,05)$. Fonte: Autores.

No $10^{\circ}$ dia de ensaio, observou-se o mesmo padrão quanto a CF e ICF registrada anteriormente. No entanto, $P$. australis SA18 obteve uma taxa máxima de CF (100\%) no meio contaminado com $10 \mathrm{mg} / \mathrm{mL}$ de glyphosate e aumento do CF nas concentrações de $30 \mathrm{mg} \mathrm{mL}^{-1}(51 \%)$ e $50 \mathrm{mg} \mathrm{mL}^{-1}$ (33\%) (Fig. 3A). O isolado H. fendleri SA41, que havia demonstrado capacidade de tolerar o contaminante, manteve-se constante, sem aumentos significativos da $\mathrm{CF}$ ao $10^{\circ}$ dia. Também, vale destacar o isolado D. dimorphosporum SA09 que obteve uma melhora na sua taxa de CF nas concentrações $10 \mathrm{mg} \mathrm{mL}^{-1}(62 \%)$, $30 \mathrm{mg} \mathrm{mL}^{-1}(43 \%)$ e $50 \mathrm{mg} \mathrm{mL}^{-1}(40,7 \%)$ comparado ao $5^{\circ}$ dia, mostrando uma adaptação ao ambiente contaminado após o período analisado e diminuindo a taxa de ICF em mais de $25 \%$ em todas as concentrações (Fig. 3B). Polyporus sp. SA23 manteve as mesmas taxas de CF comparado com o $5^{\circ}$ dia, tendo assim as maiores taxas ICF novamente nas concentrações 
10mg mL $\mathrm{mL}^{-1}(65,5 \%), 30 \mathrm{mg} \mathrm{mL}^{-1}(83 \%)$ e $50 \mathrm{mg} \mathrm{mL}^{-1}(83,5 \%)$, seguido do L. crinitus SA37, 10mg mL $\mathrm{mL}^{-1}(58,5 \%), 30 \mathrm{mg} \mathrm{mL}^{-1}$ $(70,8 \%)$ e $50 \mathrm{mg} \mathrm{mL}^{-1}(81 \%)$, e por terceiro o C. bulleri SA16 com $10 \mathrm{mg} \mathrm{mL}^{-1}(50 \%), 30 \mathrm{mg} \mathrm{mL}^{-1}(68,2 \%)$ e $50 \mathrm{mg} \mathrm{mL}^{-1}(71 \%)$, esse último isolado no decorrer do $10^{\circ}$ dia teve um grande desenvolvimento na taxa de $\mathrm{ICF}$ em relação ao $5^{\circ}$ dia, demonstrando que o contaminante teve maior impacto sobre o seu desenvolvimento micelial. Além disso, alguns fungos, além de baixo crescimento, tendem a apresentar certa modificação morfológica na constituição de sua colônia, observados em meio a elevadas concentrações de glyphosate, como pode ser observado em C. bulleri SA16 (Figura 4).

Figura 3: Taxa decrescimento fúngico $(\mathrm{CF})(\mathbf{A})$ e Taxa de inibição do crescimento (ICF) do $10^{\circ}$ dia.
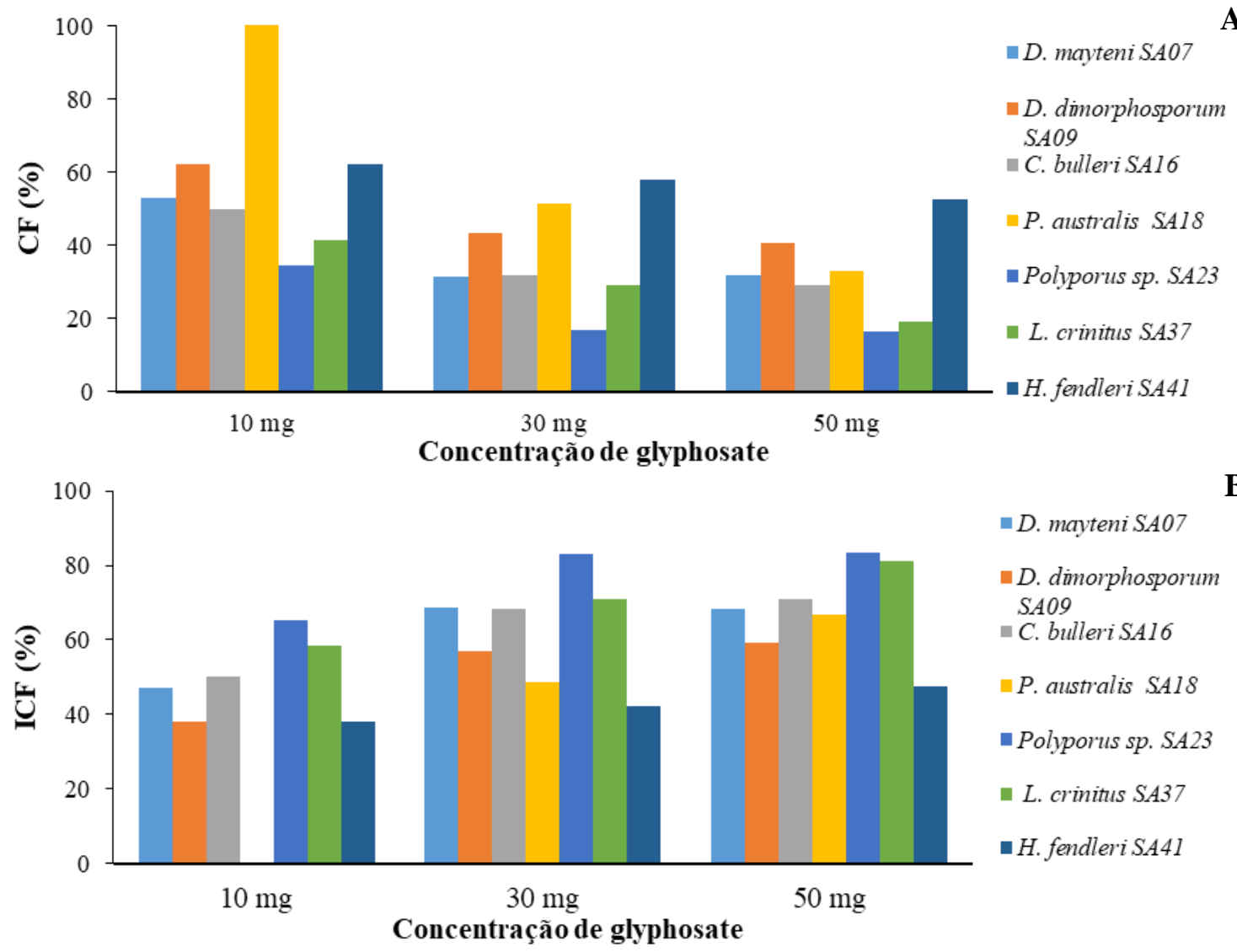

B

Fonte: Autores.

Figura 4: Crescimento de Cyathus bulleri SA16: (A) Controle; (B) $10 \mathrm{mg} \mathrm{mL}^{-1}$, (C) $30 \mathrm{mg} \mathrm{mL}^{-1}$ e (D) $50 \mathrm{mg} \mathrm{mL}^{-1} \mathrm{de}$ glyphosate.

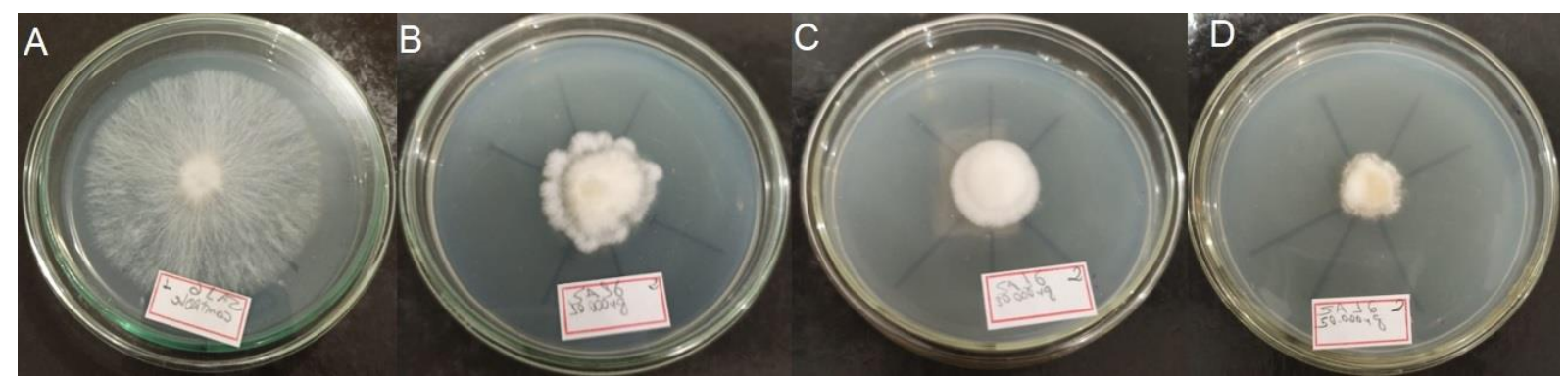

Fonte: Autores. 
Os dados de crescimento micelial médio ao $10^{\circ}$ dia ensaio (Tabela 5) demonstram que a maioria dos fungos cresceram até o limite da placa de Petri no grupo controle, mesmo contendo uma concentração menor de nutrientes no meio de cultura empregado, exceto os fungos Cyathus bulleri SA16 e Hypoxylon fendleri SA41, que tiverem um desenvolvimento mais lento. Já Polyporus sp. SA23 foi que teve menor desenvolvimento em todas as concentrações contendo o herbicida em relação aos outros espécimes, demonstrando sensibilidade ao contaminante. P. australis SA18 destacou-se obtendo maior crescimento micelial e diferente estatisticamente dos demais fungos nas concentrações de $10 \mathrm{mg} \mathrm{mL}^{-1}$ e $30 \mathrm{mg} \mathrm{mL}^{-1}$ (p $\leq 0,05$ ). Desde os testes qualitativos, verificou-se a existência de uma certa habilidade destas espécies quanto ao desenvolvimento micelial em substratos contendo compostos químicos, como observado no teste do ácido gálico e descoloração do corante RBBR. Nos testes de tolerância, tanto ao $5^{\circ}$ quanto $10^{\circ}$ dia $P$. australis SA18 apresentou as maiores taxas de CF, ICF e crescimento médio micelial estatisticamente diferente dos demais fungos. Assim, os resultados nos levam a indicação deste fungo com sendo capaz de superar o estresse da toxicidade em um ambiente contaminado, podendo assim degradar o composto.

Tabela 5: Crescimento radial (mm) depois de 10 dias em contato com diferentes concentrações de glyphosate.

\begin{tabular}{|c|c|c|c|c|c|c|c|}
\hline \multicolumn{8}{|c|}{ Fungos } \\
\hline & $\begin{array}{l}\text { D. mayteni } \\
\text { SA07 }\end{array}$ & $\begin{array}{c}\text { D. dimorphosporum } \\
\text { SA09 }\end{array}$ & $\begin{array}{l}\text { C. bulleri } \\
\text { SA16 }\end{array}$ & $\begin{array}{l}\text { P. australis } \\
\text { SA18 }\end{array}$ & $\begin{array}{c}\text { Polyporus sp. } \\
\text { SA23 } \\
\end{array}$ & $\begin{array}{l}\text { L. crinitus } \\
\text { SA37 } \\
\end{array}$ & $\begin{array}{l}\text { H. fendleri } \\
\text { SA41 }\end{array}$ \\
\hline Controle & $48,00 \pm 0 \mathrm{Aa}$ & $48,00 \pm 0 \mathrm{Aa}$ & $36,22 \pm 1,37 \mathrm{Ab}$ & $48,00 \pm 0 \mathrm{Aa}$ & $48,00 \pm 0 \mathrm{Aa}$ & $48,00 \pm 0 \mathrm{Aa}$ & $22,89 \pm 1,37 \mathrm{Ac}$ \\
\hline $10 \mathrm{mg} \mathrm{mL}^{-1}$ & $25,33 \pm 1,33 \mathrm{Bbc}$ & $29,83 \pm 6,11 \mathrm{Bb}$ & $18,11 \pm 0,15 \mathrm{Bd}$ & $48,00 \pm 0 \mathrm{Aa}$ & $16,61 \pm 0,81 \mathrm{Bd}$ & $19,89 \pm 0,59 \mathrm{Bcd}$ & $14,22 \pm 0,59 \mathrm{Bd}$ \\
\hline $30 \mathrm{mg} \mathrm{mL}^{-1}$ & $15,00 \pm 0,67 \mathrm{Cbc}$ & $20,72 \pm 0,48 \mathrm{Cab}$ & $11,50 \pm 1,67 \mathrm{Ccd}$ & $24,61 \pm 5,37 \mathrm{Ba}$ & $8,11 \pm 1,70 \mathrm{Ccd}$ & $14,00 \pm 1,78 \mathrm{Ccd}$ & $13,22 \pm 0,48 \mathrm{Bbcd}$ \\
\hline $\mathrm{CV} \%$ & & & & $11,14 \%$ & & & \\
\hline
\end{tabular}

Médias seguidas de mesma letra, minúscula na coluna e maiúscula na linha, não diferem entre si pelo teste de Tukey (p $\leq 0,05)$. Fonte: Autores.

\section{Discussão}

O processo de isolamento e seleção de organismos com potencial em degradar contaminantes ambientais é fundamental para que programas em biorremediação possam ser idealizados. Nesse sentido, os resultados obtidos nos ensaios qualitativos e quantitativos que foram realizados nesse trabalho trazem importantes informações e corroboram com diversos relatos encontrados na literatura.

O teste com o ácido gálico permite detectar a presença de enzimas do complexo fenoloxidases, empregadas na biodegradação de xenobióticos. Neste trabalho, obteve-se $60 \%$ de resposta positiva, reduzindo o número de isolados para prosseguimento dos estudos de seleção de fungos promissores. Resultados similares são relatados na literatura, tais como os encontrados em Lee et al. (2014), Santana et al. (2016), Souza et al. (2016) e Lee et al. (2020). Todos esses trabalhos indicam a importância desse método para triagem inicial de fungos com potencial em biorremediação.

A avaliação da capacidade de descoloração do corante RBBR permitiu refinar a seleção dos fungos. A inserção dos isolados em um meio contendo um composto que apresenta estrutura molecular semelhante ao antraceno, um Hidrocarboneto Policíclico Aromático (HPA) altamente hidrofóbico e recalcitrante, pode demonstrar a respostas destes fungos frente a presença de um xenobiótico. Nesses ensaios, a descoloração evidencia que a molécula do corante está sofrendo a ação de enzimas produzidas pelos fungos. Neste estudo, observou-se que $45 \%$ dos isolados testados possuem essa capacidade. Resultados similares foram encontrados por Lenhard (2006) e Santana, et al (2016). Há também trabalhos que indicam maior percentual de teste positivo para descoloração do RBBR e relação com a produção de lignina peroxidase, manganês peroxidase e lacase, enzimas conhecidas pela capacidade de degradar xenobióticos (Lee et al., 2014; Lee et al., 2020). 
A avaliação da tolerância ao contaminante de interesse é um importante atributo a ser avaliado. Eman et al. (2013) observaram que o processo de degradação e mineralização do herbicida glyphosate está diretamente relacionado à atividade e capacidade de crescimento na presença de tal composto. Assim, fungos que apresentam elevada taxa crescimento micelial podem indicar certa habilidade prática para biorremediação de ambientes contaminados. Além disso, as taxas de crescimento são muito importantes para extrapolação da capacidade potencial de colonização no campo como fornece uma boa indicação da velocidade com que um fungo é capaz de colonizar e atravessar um substrato (Nyakundi et al., 2011). Dessa forma, a obtenção de fungos com essa habilidade tem sido tratada na literatura como um aspecto relevante para avalição.

Embora o uso de bactérias em estudos sobre tolerância e biodegradação de herbicidas sejam mais frequentes, diversos estudos têm demonstrado a habilidade de fungos isolados do solo com capacidade de crescer em meio de cultura contendo glifosato, tais como: Alternaria sp., Aspergillus niger, Scopulariopsis sp., Trichoderma viride e T. harzianum. Há menção de fungos que também utilizam glifosato como única fonte de fósforo e nitrogênio, como Aspergillus favi e A. niger, Penicillium simplicissimum, Mucor sp., Penicillium janthinellum, Alternaria alternata, Trichoderma viride, Aspergillus niger e Fusarium oxysporum, Verticillium sp. e Acremonium sp. A degradação de pesticidas como terbutilazina, difenoconazol e pendimethalin já foram registradas por Fusarium oxysporum, Lentinula edodes, Penicillium brevicompactum e Lecanicillium saksenae (Adelowo et al., 2014; Arfarita et al., 2014; Javaid et al., 2016; Carranza et al. 2017).

A grande maioria dos fungos mencionados acima são representantes do Filo Ascomicota. No entanto, a literatura tem apontado que os fungos da podridão branca, tais como Phanerochaete chrysosporium, Pleurotus sp, e Trametes sp. tem capacidade comprovada de degradação e mineralizar vários cloroaromáticos, HPAs e Trinitotolueno (TNT), compostos ainda mais complexos em nível molecular quando comparado ao glyphosate (Harms et al., 2011).

Nessa pesquisa, os melhores resultados de tolerância a presença de diferentes concentrações de glyphosate foram obtidos por $P$. australis SA18, seguido de D. dimorphosporum SA09. No entanto, P. australis SA18, demonstrando uma grande capacidade de crescimento micelial e baixo índice de inibição do crescimento in vitro, mesmo em dosagens de glyphosate similares àquelas aplicadas em campo. Ambos fungos mencionados são representantes do Filo Basidiomicetos. Esse grupo de organismos apresentam um complexo grupo de exoenzimas ligninolíticas utilizadas na decomposição de lignina e conhecidos pela habilidade de mineralizar diversos compostos químicos orgânicos co-metabolicamente quando na presença de um substrato adicional com fonte de carbono e energia (Harms et al., 2011; Lee et al., 2014; Lee et al., 2020). Enfim, isso confirma a promissora capacidade dos fungos em lidar com a presença de xenobióticos, principalmente os fungos da podridão branca.

Há relatos de resultados promissores na degradação do glyphosate por basidiomicetos utilizando MnP e lacase em apenas 24 horas de ensaios in vitro, ocasionando a degradação completa do herbicida. Além disso, é que conhecido que 22 pesticidas e alguns de seus metabólitos já foram degradados pelas enzimas ligninolíticas, sendo que Cloroxuron, Prometrina e Terbutryn foram mineralizados, enquanto mais de $80 \%$ do quantidades originais de Isoproturon, Metoxuron e Metribuzin foram degradados após 6 dias de incubação (Pizzul et al., 2009).

Por fim, os resultados desse trabalho indicam que o basidiomiceto $P$. australis SA18 é um recurso genético importante para novos estudos que avaliem a produção de enzimas ligninolíticas e sua relação com a biodegradação e mineralização do glyphosate, bem como a possibilidade de pesquisa com consórcios microbianos e sua eficácia visando a biorremediação de solos agrícolas contaminados.

\section{Considerações}

Todos os fungos avaliados nesse trabalho foram tolerantes ao glyphosate, destacando-se Phanerochaete australis SA18 que apresentou as maiores taxas de crescimento e maior tolerância ao herbicida, sendo o mais indicado para estudos 
posteriores e continuados com intuito de avaliar o potencial na produção de enzimas ligninolíticas, biodegradação e mineralização de glyphosate em solos contaminados. O fungo selecionado neste trabalho também poderá auxiliar em novas pesquisas que avaliem o potencial de consórcios microbianos para descontaminação de solos agrícolas. Enfim, estudos como o deste trabalho são de grande importância, pois proporcionam dados básicos para elaboração de futuros programas de biorremediação de ambientes contaminados com herbicidas, contribuindo assim para a mitigação de impactos ambientais causados pela agricultura intensiva.

\section{Agradecimentos}

Os autores dedicam esse trabalho ao pesquisador da Universidade Estadual de Maringá (UEM) e colaborador nesse trabalho, Dr. João Alencar Pamphile (in memoriam), vítima da Covid-19.

\section{Referências}

Adelowo, F. E., Olu-Arotiowa, O. A., \& Amuda, O. S. (2014). Biodegradation of Glyphosate by Fungi Species. Advances in Bioscience and Bioengineering, 104-118. https://www.semanticscholar.org/paper/Biodegradation-of-Glyphosate-by-Fungi-Species-Adelowo-Olu-arotiowa/b6823c1 f061b431ffbbed8628 1f0f5f86e dc9dbd?sort=rele vance \&citationIntent=methodology

Amazonas, M. A. L. A. (2003). Biodiversidade de macrofungos e potencial de uso para o desenvolvimento sustentável. Embrapa Florestas. https://www.embrapa.br/busca-de-publicacoes/-/publicacao/308602/biodiversidade-de-macrofungos-e-potencial-de-uso-para-o-desenvolvimento-sustentavel.

Ambiente Brasil. (n.d.). https://ambientes.ambientebrasil.com.br/unidades_de_conservacao/estacao_ecologica/estacao_ecologica_serra_das_araras.html.

Araújo, A. S. F. (2002) Biodegradação, extração e análise de glifosato em dois tipos de solos [Dissertação de Mestrado, Universidade de São Paulo]. https://doi.org/10.11606/D.11.2002.tde-05092002-161341

Arfarita, N., Imai, T., \& Prasetya, V. (2014). Potential use of soil-born fungi isolated from treated soil in Indonesia to degrade glyphosate herbicide. Journal of Degraded and Mining Lands Management, 63-68. https://jdmlm.ub.ac.id/index.php/jdmlm/article/view/28. DOI: 10.15243/jdmlm.2014.012.063.

Argumedo-delira, R., Alarcon, A., Ferrera-Cerrato, R., Almaraz, J. J., \& Peña-Cabriales, J. J. (2012). Tolerance and growth of 11 Trichoderma strains to crude oil, naphthalene, phenanthrene and benzo[a]pyrene. Journal of Environmental Management, v. 95, n. SUPPL., p. S291-S299. https://doi.org/10.1016/j.jenvman.2010.08.011

Barbosa, V. F. (2010). Caracterização do perfil da ação do ácido gálico e seus derivados sobre processos oxidativos in vitro e ex vivo [Dissertação de Mestrado Universidade Estadual Paulista]. https://repositorio.unesp.br/handle/11449/87981

Barroso, A. A. M., \& Murata, A. T. (2021). Matologia: estudos sobre plantas daninhas (1ºd.). Fábrica de Palavras.

Benbrook, C. M. (2019). How did the US EPA and IARC reach diametrically opposed conclusions on the genotoxicity of glyphosate-based herbicides? Environmental Science Europe. https://doi.org/10.1186/s12302-018-0184-7.

Berlinck, R. G. S. (2012). Bioprospecção no Brasil: um breve histórico. Ciência e Cultura. http://dx.doi.org/10.21800/S0009-67252012000300010

Bononi, V. L. R., Machado, K. M. G., Matheus, D. R., \& Vitali, V. M. (2008). Biodegradação de organoclorados no solo por basidiomicetos lignocelulolíticos. In: Melo, I. S., Azevedo, J. L. Microbiologia Ambiental. Embrapa Meio Ambiente.

Carranza, C. S., Barberis, C. L., Chiacchiera, S. M., \& Magnoli, C. E. (2017). Assessment of growth of Aspergillus spp. from agricultural soils in the presence of glyphosate. Rev Argent Microbiol, 384-393. https://doi.org/10.1016/j.ram.2016.11.007

Castellani, A. (1939). Viability of some pathogenic fungi in distilled water. Journal of Tropical Medicine and Hygiene, 225-226.

Castro júnior, J. V., Selbach, P. A., \& Záchaayub, M. A. (2006). Avaliação do efeito do herbicida glifosato na microbiota do solo. Pesticidas: Revista de Ecotoxicologia e Meio Ambiente, 21-30. https://revistas.ufpr.br/pesticidas/article/view/7476/5345

Catarino, S. R. M. (2016). Biorremediação [Monografia de Mestrado Universidade de Coimbra] https://estudogeral.uc.pt/bitstream/10316/41900/2/Monografia\%203.pdf

Colla, L. M., Primaz, A. L., Lima, M., Bertolin, T. E., \& Costa, J. A. V. (2008). Isolamento e seleção de fungos para biorremediação a partir de solo contaminado com herbicidas triazínicos. Ciências e Agrotecnologia, 809-813. https://doi.org/10.1590/S1413-70542008000300016

Correa, L. O., Bezerra, A. F. M., Honorato, L. R. S., Cortez, A. C. A., Souza, J. V. B., \& Souza, E. S. Amazonian soil fungi are efficient degraders of glyphosate herbicide, novel isolates of Penicillium, Aspergillus, and Trichoderma. Brazilian Journal of Biology. https://doi.org/10.1590/1519-6984.242830

Davidson, W. R., Campbell, W. A., \& Baisdell, D. J. (1938). Differentiations of wood-decaying fungy by their reactions on gallic or tanic acid medium. Journal of Agricultural Research, 683-695. https://naldc.nal.usda.gov/download/IND43969196/PDF 
Eman, A., Sadik, M.W., Abdel-Megeed, A., Suliman, A., \& Sholkamy, E. N. (2013). Biodegradation of Glyphosate by Fungal Strains Isolated from Herbicides Polluted-Soils in Riyadh Area. British Journal of Environmental Sciences, 7-29. https://www.eajournals.org/journals/british-journal-ofenvironmental-sciences-bjes/vol-1-issue-1-december-2013/biodegradation-glyphosate-fungal-strains-isolated-herbicides-polluted-soils-riyadh-area/

Filho, S. A, Silva, C. G. N., \& Bigi, M. F. M. A. (2014). Bioprospecção e biotecnologia. Parcerias Estratégicas. Brasília-DF, v. 19, n. 38, p. 45-80, 2014. Disponível em: http://seer.cgee.org.br/index.php/parcerias_estrategicas/article/viewFile/732/672

Forlani, G., Mangiagalli, A., Nielsen, E., \& Suardi, C. M. (1999). Degradation of the phosphonate herbicide glyphosate in soil: evidence for a possible involvement of unculturable microorganisms. Soil Biology and Biochemistry, 991-997. https://doi.org/10.1016/S0038-0717(99)00010-3

Gaylarde, C. C., Bellinaso, M. D. L., \& Manfio, G. P. (2005). Biorremediação: Aspectos Biológicos e Técnicos da Biorremediação de Xenobióticos. Biotecnologia, Ciência $e$ Desenvolvimento, $\quad 36-43$. https://edisciplinas.usp.br/pluginfile.php/4144372/mod_resource/content/1/Biorremediac\%CC\%A7a\%CC\%83o\%20-\%20Artigo\%201.pdf

Glass, N. L., \& Donaldson, G. (1995). Development of primer sets designed for use with PCR to amplify conserved genes from filamentous ascomycetes. Applied Environmetal Microbiology, 1323-1330. https://www.ncbi.nlm.nih.gov/pmc/articles/PMC167388/

Guerrero, R. T., \& Homrich, M. H. (1999). Fungos Macroscópicos comuns no Rio Grande do Sul (2nd ed.). Universidade/UFRGS.

Harms, H., Schlosser, D., \& Wick, L. Y. (2011). Untapped potential: exploiting fungi in bioremediation of hazardous chemicals. Nature Reviews Microbiology, 177-192. https://doi.org/10.1038/nrmicro2519

Hough, R. L. A world view of pesticides. Nature Geoscience, 14, 183-184. https://doi.org/10.1038/s41561-021-00723-2

Javaid, M. K., Ashiq, M., \& Tahir, M. (2016). Potential of biological agents in decontamination of agricultural soil. Scientifca. https://doi.org/10.1155/2016/1598325.

Katoh, K.., \& Toh, H. (2008). Recent developments in the MAFFT multiple sequence alignment program. Briefings in Bioinformatics, 86-98. http://dx.doi.org/10.1093/bib/bbn013

Kim, Y-J. (2007). Antimelanogenic and antioxidant properties of gallic acid. Biological and Pharmaceutical Bulletin, 1052-1055. https://doi.org/10.1248/bpb.30.1052

Landrigan, P., \& Belpoggi, F. (2018). The need for independent research on the health effects of glyphosate-based herbicides. Environmental Health https://doi.org/10.1186/s12940-018-0392-z

Lee, A.H., Lee, H., Heo, Y.M., Lim,Y. W., Kim, C., Kim, G., Chang, W., \& Kim, J. (2020). A proposed stepwise screening framework for the selection of polycyclic aromatic hydrocarbon (PAH)-degrading white rot fungi. Bioprocess Biosyst Eng, 767-783. https://doi.org/10.1007/s00449-019-02272-w

Lee, H., Jang, Y., Choi, Y., Kim, M., Lee, J., Lee, H., Hong, J., Lee, Y. M., Kim, G., \& Kim, J. (2014). Biotechnological procedures to select white rot fungi for the degradation of PAHs. Journal of Microbiological Methods, 56-62. https://doi.org/10.1016/j.mimet.2013.12.007

Lenhard, D. C. (2006). Descoloração de corantes têxteis reativos por fungos ligninolíticos e por lacase [Dissertação de Mestrado, Universidade Estadual de Maringá]. http://www.dominiopublico.gov.br/pesquisa/DetalheObraForm.do?select_action=\&co_obra=157422

Maggi, F., Cecilia, D., Tang, F. H. M., \& McBratney, A. (2020). The global environmental hazard of glyphosate use. Science of the Total Environment. https://doi.org/10.1016/j.scitotenv.2020.137167

Mahmood I., Imadi S.R., Shazadi K., Gul A., \& Hakeem K. R. (2016). Effects of Pesticides on Environment. Plant, Soil and Microbes. https://doi.org/10.1007/978-3-319-27455-3_13

Malty, J. S., siqueira, J. O., \& Moreira, F. M. S. (2006). Efeitos do glifosato sobre microrganismos simbiotróficos de soja, em meio de cultura e casa de vegetação. Pesquisa Agropecuária Brasileira, 285-291. https://doi.org/10.1590/S0100-204X2006000200013

Monteiro, P. H. R. et al. (2012). Estudo sobre a viabilidade de remediação de pesticidas por ectomicorrizas e avaliação da sua tolerância em exposição ao glifosato. A responsabilidade socioambiental da pesquisa agrícola. https://www.alice.cnptia.embrapa.br/alice/handle/doc/934518

Moraes, P. V. D., \& Rossi, P. (2010). Comportamento ambiental do glifosato. Scientia Agraria Paranaensis, 22-35. http://erevista.unioeste.br/index.php/scientiaagraria/article/view/5258

Nyakundi, W. O., Magoma, G., Ochora, J., \& Nyende, A. B. (2011). Biodegradation of diazinon and methomyl pesticides by whiterot fungi from selected horticultural farms in rift valley and central kenya. Journal of Applied Technology in Environmental Sanitation, 107-124. http://ir.jkuat.ac.ke/bitstream/handle/123456789/948/BIODEGRADATION\%20OF\%20DIAZINON\%20AND\%20METHOMYL\%20PESTICIDES\%20BY\%2 0WHITE.pdf?sequence=1\&isAllowed=y

Nylander, J. A. A. MrModeltest Version 2. Program distributed by the author. Evolutionary Biology Centre, Uppsala University, Uppsala, 2004. https://www.researchgate.net/publication/285805344_MrModeltest_V2_Program_Distributed_by_the_Author

O'donnell, K., \& Cigelnik, E. (1997). Two divergent intragenomic rDNA ITS2 types within a monophyletic lineage of the fungus Fusarium are nonorthologous. Molecular Phylogenetics and Evolution, 103-116. https://doi.org/10.1006/mpev.1996.0376

Peillexa, C., \& Pelletier, M. (2020). The impact and toxicity of glyphosate and glyphosate-based herbicides on health and immunity. Journal of Immunotoxicology, 163-174. https://doi.org/10.1080/1547691X.2020.1804492.

Pietrobon, C. B., \& Senem, J. V. (2015). Avaliação dos efeitos toxicológicos do herbicida glifosato sore o estomago de ratos Wistar machos. Revista Cultivando o Saber, 172-183. https://www.fag.edu.br/upload/revista/cultivando_o_saber/55d1eed313659.pdf 
Research, Society and Development, v. 11, n. 1, e31411124782, 2022

(CC BY 4.0) | ISSN 2525-3409 | DOI: http://dx.doi.org/10.33448/rsd-v11i1.24782

Pizzul, L., Castillo, M. P., \& Stenstrom, J. (2009). Degradation of glyphosate and other pesticides by ligninolytic enzymes. Biodegradation,751-759. DOI $10.1007 / \mathrm{s} 10532-009-9263-1$.

Rainert, K. T., Chicatto, J. L., Gonçalves, M. J., Vaz, D. A., \& Tavares, L. B. B. (2016). Adisorção do corante Reactive Blue 19 por bainha do palmito Pupunha in natura. IV Congresso cientifico têxtil e moda-CONTEXMOD. http://www.contexmod.net.br/index.php/quarto/article/view/425

Rambaut, A. FigTree version 1.3.1. (computer program), 2009. http://tree.bio.ed.ac.uk/software/figtree/. Acesso em: 17 fev. 2021.

Rehner, S. A., \& Samuels, G. J. (1994). Taxonomy and phylogeny of Gliocladium analysed from nuclear large subunit ribosomal DNA sequences. Mycological Research, 625-634. https://doi.org/10.1016/S0953-7562(09)80409-7

Rodriguez, J. P. G. (2014). Identificação dos compostos produzidos na degradação do corante Remazol Brilliant Blue R (RBBR) pela ação do fungo do ambiente marinho Tinctoporellus [Dissertação de Mestrado, Universidade de São Paulo]. https://teses.usp.br/teses/disponiveis/75/75135/tde-10062014104028/pt-br.php

Ronquist, F., Teslenko, M., Mark, P., Ayres, D. L., Darling, A., Höhna, S., Larget, B., Liu, L., Suchard, M. A., \& Huelsenbeck, J. P. (2012). MrBayes 3.2: Efficient Bayesian phylogenetic inference and model choice across a large model space. Systematic Biology, 539-542. https://doi.org/10.1093/sysbio/sys029

Saccaro Júnior, N. L. (2011). Desafios da bioprospecção no Brasil. Instituto de Pesquisa Econômica Aplicada-IPEA. https://www.ipea.gov.br/portal/index.php?option=com_content\&view=article\&id=7066

Santana, M. D. F. Rodrigues, L. S. I., Amaral, T. S., \& Pinheiro, Y. G. (2016). Fenoloxidases e biodegradação do corante têxtil azul brilhante blue r (RBBR) para três espécies de macrofungos coletados na Amazônia. SasBios: Revista de Saúde e Biologia, 53-60. https://tratamentodeagua.com.br/wpcontent/uploads/2017/04/fenoloxidase-e-biodegradacao-corante-textil-azul-brilhante-de-remazol-r-rbbr-para-tres-especies-de-macrofungos-coletadas-naamazonia.pdf

Singh, S., Kumar, V., Datta, S., Wani, A. B., Dhanjal, D. S., Romero, R., \& Singh, J. (2020a). Glyphosate uptake, translocation, resistance emergence in crops, analytical monitoring, toxicity and degradation: a review. Environ Chem Lett, 663-702. https://doi.org/10.1007/s10311-020-00969-z

Singh, S., Kumar, V., Gill, J.P.K., Datta, S., Singh, S., Dhaka, V., Kapoor, D., Wani, A.B., Dhanjal, D.S., Kumar, M., Harikumar, S.L., \& Singh, J. (2020b). Herbicide Glyphosate: Toxicity and Microbial Degradation. Int J Environ Res Public Health. doi: 10.3390/ijerph17207519

Souza, H. M. L., Sette, L. D., Mota, A. J., Neto, J. F. N., Rodrigues, R., Oliveira, T. B., Oliveira, F. M., Oliveira, L. A., Barroso, H. S., \& Zanotto, S. P. (2016). Filamentous fungi isolates of contaminated sediment in the amazon region with the potential for benzo(a)pyrene degradation. Water, Air, \& Soil Pollution. https://doi.org/10.1007/s11270-016-3101-y

Souza, H. M. de L., Barreto, L. R., Mota, A. J. da, Oliveira, L. A. de, Barroso, H. dos S., \& Zanotto, S. P. (2017). <b\&gt,Tolerance to Polycyclic Aromatic Hydrocarbons (PAHs) by filamentous fungi isolated from contaminated sediment in the Amazon region. Acta Scientiarum. Biological Sciences, 39(4), 481488. https://doi.org/10.4025/actascibiolsci.v39i4.34709

Vacondio, B., Birolli, w. G., Seleghim, M. H. R., Gonçalvez, S., Vasconcellos, S. P., \& Porto, A. L. M. (2015). Screening of Marine-derived Fungi Isolated from the sponge Didemnun ligulum for Biodegradation of Pentachlorophenol. Advances in Bioremediation of Wastewater and Polluted Soil, 193-225. http://dx.doi.org/10.5772/60777

Vilgalys, R., \& Hester, M. (1990). Rapid genetic identification and mapping of enzymatically amplified ribosomal DNA from several Cryptococcus species. Journal of Bacteriology, 4239-4246. https://doi.org/10.1128/jb.172.8.4238-4246.1990

White, T. J., Bruns, T., \& Taylor, J. (1990). Amplification and Direct Sequencing of Fungal Ribosomal RNA Genes for Phylogenetics. Academic Press, 315322. https://doi.org/10.1016/B978-0-12-372180-8.50042-1

Zhan, H., Feng, Y., Fan, X. \& Chen, S. (2018). Recent advances in glyphosate biodegradation. Applied Microbiology and Biotechnology, https://doi.org/10.1007/s00253-018-9035-0 